\title{
Mechanical Properties of Tibetan Rubble Stone Masonry Under Uniaxial Compression
}

\section{Yu Wang}

Chongqing University

Tiejun Zhou ( $\nabla$ arch_ztj@cqu.edu.cn )

Chongqing University

\section{Ruheng Wang}

Southwest University of Science and Technology

\section{Yuan Wang}

Southwest University of Science and Technology

\section{Research Article}

Keywords: Rubble stone masonry, Compression test, Failure mechanism, Stress-strain, Compressive strength

Posted Date: December 13th, 2021

DOI: https://doi.org/10.21203/rs.3.rs-1147825/v1

License: (c) (1) This work is licensed under a Creative Commons Attribution 4.0 International License. Read Full License 


\title{
1 Mechanical Properties of Tibetan Rubble Stone 2 Masonry under Uniaxial Compression
}

\author{
3 Yu Wang ${ }^{1,2}$,Tiejun Zhou ${ }^{1^{*}}$, Ruheng Wang2, YuanWang ${ }^{2}$ \\ 41 School of Architecture and Urban Planning, Chongqing University, Chongqing 400044, P.R. China; \\ $5{ }^{2}$ School of Civil and Architecture Engineering, Southwest University of Science and Technology, \\ 6 Mianyang621010, P.R. China; \\ 7 * Correspondence: Tiejun Zhou, arch_ztj@cqu.edu.cn;
}

Received: ...; Accepted: ...; Published:

Abstract: Basic mechanical properties of Tibetan rubble stone masonry, a unique architectural structure in western China, may affect the bearing capacity of architectural structures. In this study, a compression test was carried out on a Tibetan rubble prism to investigate its failure mechanism and stress-strain characteristics under uniaxial compression. Based on the experimental results, we obtained two simple compression constitutive models for Tibetan rubble stone masonry, established equations applicable to predicting the compressive strength of Tibetan rubble stone masonry, and obtained a relationship between compressive strength and the elasticity modulus through a regression analysis.

Keywords:Rubble stone masonry; Compression test; Failure mechanism; Stress-strain;

\section{Introduction}

Tibetan rubble stone masonry, a unique architectural structure in western China, refers to Compressive strength

masonry composed of natural rubble, clay, and waste materials. Yellow clay caulking and gravel caulking masonry form the most common types of Tibetan walls. The defects of natural materials (e.g., irregular shapes of stones, low flexural strength, poor bonding performance of clay, and poor resistance to rain wash) significantly reduce the stress performance and durability of Tibetan rubble stone masonry walls, resulting in poor compression performance of Tibetan rubble stone masonry. Currently, there are few research results available due to the regional characteristics of Tibetan rubble stone masonry.

Several experimental studies have been performed regarding compressive constitutive models [1-4] and strength prediction models of brick and tuff masonry, which are useful as references for establishing prediction equations of failure mechanisms, stress-strain behavior, and strength of Tibetan rubble stone masonry. Common empirical constitutive models of masonry include polynomial type, rational fraction type, and two-step type models. Table 1 gives equations that represent these different modeling types. Nazar et al. [1] used the simple quartic polynomial in Equation (1) to predict the stress-strain relationship for interlocking grouted stabilized sand-flash brick masonry under uniaxial cyclic loading and unloading. By modifying the concrete constitutive model, Cavaleri et al. [2] obtained a rational fraction equation for stress-strain of limestone, i.e., Equation (2), based on experimental data. Based on the Kent-Park model, Kaushik et al. [4] developed a two-step equation suitable for clay brick masonry. This model expressed the first section, i.e., the first $10 \%$ of the ascending section and the descending section, in parabolic form (Equation (3)), and linearly expressed the remainder 
Table 1Typical stress-strain models for the compressive strength of rubble stone masonry

\begin{tabular}{|c|c|c|c|}
\hline Study & Equation & & Comments \\
\hline Nazar et al. [1] & $\sigma=A \varepsilon^{4}+B \varepsilon^{3}+C \varepsilon^{2}+D \varepsilon$ & $(1)$ & $\begin{array}{l}\text { Suggested values of A, B, C and D: } \\
-0.1394,0.9480,-2.4224 \text { and } 2.6158\end{array}$ \\
\hline Cavaleri et al. [2] & $\sigma=\frac{A \varepsilon+(D-1) \varepsilon^{2}}{1+(A-2) \varepsilon+D \varepsilon^{2}}$ & $(2)$ & $\begin{array}{l}\text { Suggested values of A and D: } 2.8 \\
\text { and } 1.2\end{array}$ \\
\hline Kaushik et al. [4] & $\begin{array}{l}\sigma=2 \varepsilon-\varepsilon^{2} \\
\sigma=0.9-\frac{0.7}{\mu-\varepsilon_{0.9}}\left(\varepsilon-\varepsilon_{0.9}\right)\end{array}$ & $\begin{array}{l}(3) \\
(4)\end{array}$ & $\begin{array}{l}\mathcal{\varepsilon} \in\left[0, \varepsilon_{0.9}\right] \\
\varepsilon \in\left[\varepsilon_{0.9}, \mu\right]\end{array}$ \\
\hline
\end{tabular}

The compressive strength of masonry can be predicted using the strengths of its base materials. Eurocode 6 [5] proposed a simple analysis model that expressed the relationship between the strength of the masonry $\left(f_{c}\right)$, the block elements $\left(f_{b}\right)$, and the mortar $\left(f_{m}\right)$ :

$$
f_{c}=K f_{b}^{\alpha} f_{m}^{\beta}
$$

In Equation (5), $K, \alpha$, and $\beta$ are all constants. The value of $K$ depends on the masonry units and mortar joint characteristics. According to Eurocode 6 [5], the value of $\mathrm{K}$ ranges from 0.4 to 0.6 , and the values of $\alpha$ and $\beta$ are 0.7 and 0.3 , respectively. This model was used in previous studies [6-8] to predict the strength of masonry constructed by specific blocks with a specific cement mortar, and those studies suggested values of $K, \alpha$, and $\beta$ based on their measured results (Table 2).

Table 2Common equations used to predict the compressive strength of rubble stone masonry

\begin{tabular}{lll}
\hline Study & Equation & \\
\hline Kaushik et al. [4] & $f_{c}=0.63 f_{b}^{0.49} \cdot f_{m}^{0.32}$ & $(6)$ \\
Eurocode 6 [5] & $f_{c}=0.5 f_{b}^{0.7} \cdot f_{m}^{0.3}$ & $(7)$ \\
Dayaratnam [6] & $f_{c}=0.275 f_{b}^{0.5} \cdot f_{m}^{0.5}$ & $(8)$ \\
Hendry and Malek [7] & $f_{c}=0.317 f_{b}^{0.531} \cdot f_{m}^{0.208}$ & (9) \\
Adrian Costigan et al. [8] & $f_{c}=0.46 f_{b}^{0.5} \cdot f_{m}^{0.5}$ & $(10)$ \\
\hline
\end{tabular}

According to Code for Design of Masonry Structures (GB 50003-2011) [9], an architectural code in China, the compressive strength of masonry structures should be calculated based on Equation (11):

$$
f_{c}=k_{1} f_{1}^{\alpha}\left(1+0.07 f_{2}\right) k_{2}
$$

Here, $f_{c}$ denotes the average compressive strength of the masonry in $\mathrm{MPa}$, and $f_{1}$ and $f_{2}$ represent the average compressive strengths of the block element and the mortar, respectively, in MPa. $k_{1}$ and $\alpha$ are the parameters related to the types of block elements and masonries used, and the values of rubble masonry are 0.22 and 0.5 respectively. $k_{2}$ denotes the corrected parameter influenced by the mortar strength, and when $\mathrm{f}_{2}<2.5, \mathrm{k}_{2}=0.4+0.24 \mathrm{f}_{2}$.

In Eurocode 6 [5], the elasticity modulus (E) and the compressive strength $\left(f_{c}\right)$ of masonry was defined as shown in Equation (12). This model has been extensively applied to brick masonry and hollow concrete block masonry $[10,11]$.

$$
E=K f_{c}
$$


To analyze the mechanical properties of rubble stone masonry in ancient European buildings, compression tests were carried out on rubble stone-like masonry walls or abandoned walls to study their failure mechanisms and strengths [12-17]. The studies used different methods (e.g., grouting and reinforcement) to consolidate the rubble stone masonry walls, and the references provided suggestions for the reinforcement and repair of rubble stone masonry structures in ancient European buildings. Results of previous studies [18-20] indicated that test costs and periods can be reduced by obtaining the compressive strength and elasticity modulus of specimens based on tests of prismatic specimens built with the same materials. Moreover, Eurocode 6 [21] also analyzed the mechanical properties of rubble stone masonry by testing prismatic specimens.

In summary, many scholars have investigated mechanical properties of traditional masonry structures, but the mechanical properties of Tibetan rubble stone masonry structures have rarely been explored. The failure mechanism of Tibetan rubble stone masonry structures greatly differs from that of conventional masonry structures [22]. In this study, by fully considering the characteristics of Tibetan rubble stone masonry (i.e., relative size, internal composition, geometric shape, and structural characteristics), representative prismatic specimens for compression tests were selected. Based on the basic mechanical parameters (e.g., compressive strength and stress-strain characteristics) of rubble stone masonry obtained through uniaxial compression loading, a compressive constitutive model was developed, a prediction equation for compressive strength was obtained, and the relationship between the compressive strength and the elasticity modulus of Tibetan rubble stone masonry was established.

\section{Base Materials of Tibetan Rubble Stone Masonry and Its Mechanical Properties}

Rubble block and yellow clay are the base materials of Tibetan rubble stone masonry, and the mechanical parameters of the two significantly influence the compressive bearing capacity of the masonry structure and the establishment of the constitutive relationship [16]. The stones used in these experiments were granite commonly found in Tibetan areas, and the strength of the stones was measured according to the Standard for Test Method of Basic Mechanics Properties of Masonry [22]. The compressive strength was obtained by a uniaxial compression test conducted on a $70 \mathrm{~mm}$ standard cubic specimen, and the elasticity modulus was determined by a test performed on a $\Phi 50 \times 100 \mathrm{~mm}$ cylindrical specimen. The tensile strength and bending strength of the materials significantly impact the masonry strength [18-20]. A bending test was carried out on a cuboid specimen with dimensions of $50 \times 50 \times 250 \mathrm{~mm}$, and a splitting tensile test was conducted on a $\Phi 50 \times 30 \mathrm{~mm}$ cylindrical specimen. These tests for rubble stone and corresponding failure modes are demonstrated in Figure 1, and the average strength values are shown in Table 3.

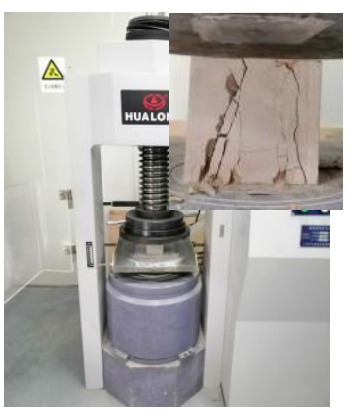

(a)

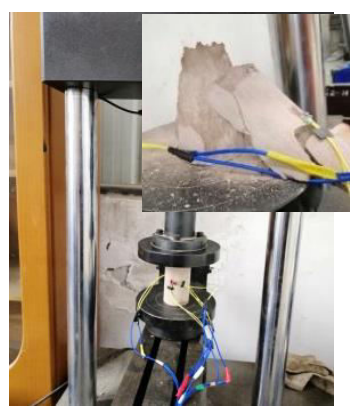

(b)

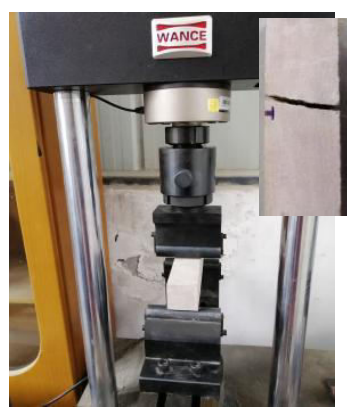

(c)

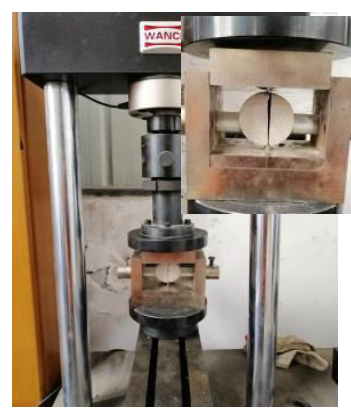

(d)

Figure 1. Testing of mechanical properties of stone samples: (a) Compressive test;(b) elasticity modulus test; (c) bending strength test; (d) splitting tensile strength test 
Table 3 Basic mechanical properties of stone elements

\begin{tabular}{cccccc}
\hline Stone & $\begin{array}{c}\text { Density } \\
\left(\mathrm{kg} / \mathrm{m}^{3}\right)\end{array}$ & $\begin{array}{c}\text { Compressive } \\
\text { strength }(\mathrm{MPa})\end{array}$ & $\begin{array}{c}\text { Bending } \\
\text { strength } \\
(\mathrm{MPa})\end{array}$ & $\begin{array}{c}\text { Tensile } \\
\text { strength } \\
(\mathrm{MPa})\end{array}$ & $\begin{array}{c}\text { Elasticity } \\
\text { modulus } \\
(\mathrm{MPa})\end{array}$ \\
\hline Granite & 2625 & 94.14 & 15.65 & 3.79 & 36.80 \\
\hline
\end{tabular}

109

Table 4Basic mechanical parameters of clay mortar

\begin{tabular}{llllll}
\hline $\begin{array}{l}\text { Bonding } \\
\text { material }\end{array}$ & $\begin{array}{l}\text { With } \\
\text { gravel or } \\
\text { not }\end{array}$ & $\begin{array}{l}\text { Initial moisture } \\
\text { content } \\
\left(\mathrm{m}_{\text {water }} / \mathrm{m}_{\text {clay }}\right)(\%)\end{array}$ & $\begin{array}{l}\text { Initial } \\
\text { density } \\
\left(\mathrm{kg} / \mathrm{m}^{3}\right)\end{array}$ & $\begin{array}{l}28 \mathrm{~d} \text { volume } \\
\text { shrinkage } \\
(\Delta \mathrm{v} / \mathrm{V})(\%)\end{array}$ & $\begin{array}{l}\text { Average } \\
\text { compressive } \\
\text { strength }(\mathrm{MPa})\end{array}$ \\
\hline Clay & No & 26.7 & 1702.7 & 15.7 & 1.0 \\
mortar & Yes & & 1763.5 & 14.5 & 1.3 \\
\hline
\end{tabular}

\section{Compression Test of Tibetan Rubble Stone Masonry Structures}

The two layers of rubble, i.e., inner and outer, bear the primary portion of the load in Tibetan stone masonry. To simplify the compression test, the middle inter-layer was removed, and a basic study was performed on the Tibetan rubble stone masonry, as shown in Figure 2(a). According to the European standard EN1052-1 [24], prismatic specimens should contain at least three layers and at least one joint. Based on the characteristics of Tibetan walls and experimental conditions, when the height to thickness ratio $(\mathrm{h} / \mathrm{t})$ is greater than 2 , the boundary effect will be insignificant [22]. The dimensions of the specimens used in this study were approximately $500 \times 300 \times 600 \mathrm{~mm}$ (length $\times$ thickness $\times$ height). For this test, eight rubble prismatic specimens in two groups were designed. Constructed together by clay (SPAi) and gravel (SPBi), respectively, the specimens in the two groups were built in batches by local traditional technology. The lengths, widths, and thicknesses of the rubble specimens ranged from 150 to $250 \mathrm{~mm}, 100$ to $200 \mathrm{~mm}$, and 40 to $70 \mathrm{~mm}$, respectively. Each layer of clay was approximately $10 \mathrm{~mm}$ thick, and the ratio of the clay's volume to the material block's volume in each specimen was near 1:4. Figure 2 shows photographs of the specimens. To ensure uniform contact between the specimens and the loading platform of the testing machine, the specimens were built on a flat plate, and the upper and lower surfaces were leveled with 1:3 mortar that had thicknesses of approximately $1 \mathrm{~cm}$ [23]. 


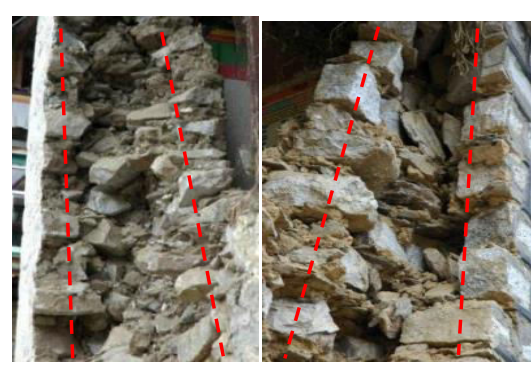

(a)

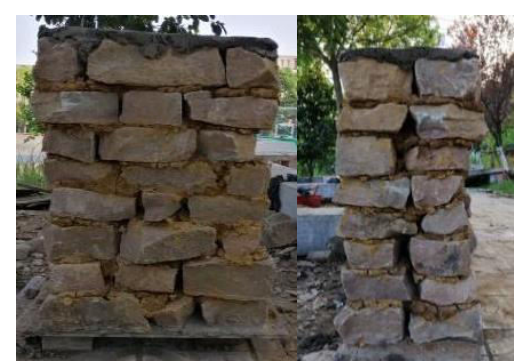

(b)

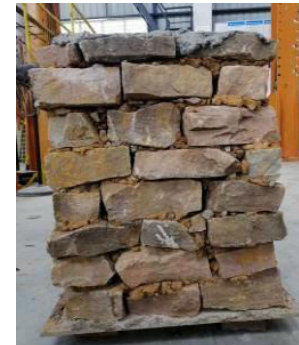

(c)

Figure 2 Cross-sectional structures and specimens of Tibetan rubble stone masonry: (a) actual cross-sectional structure of Tibetan rubble walls; (b) clay caulking specimens; (c) gravel caulking specimens

140

141

142

143

144

145

146

147

The specimens were cured under natural conditions for 28 days. Thereafter, loads were applied by a 5000-kN electro-hydraulic servo-controlled machine, which are shown in Figure 3 . Since the testing machine had great rigidity, it could apply loads at fixed strain rates. Based on prior research results $[19,20,22]$, the loading speed was chosen to be $2 \mathrm{~mm} / \mathrm{min}$. The testing machine was equipped with a built-in sensing system, and the vertical displacement of the testing machine was taken to be the vertical deformation of the specimens.
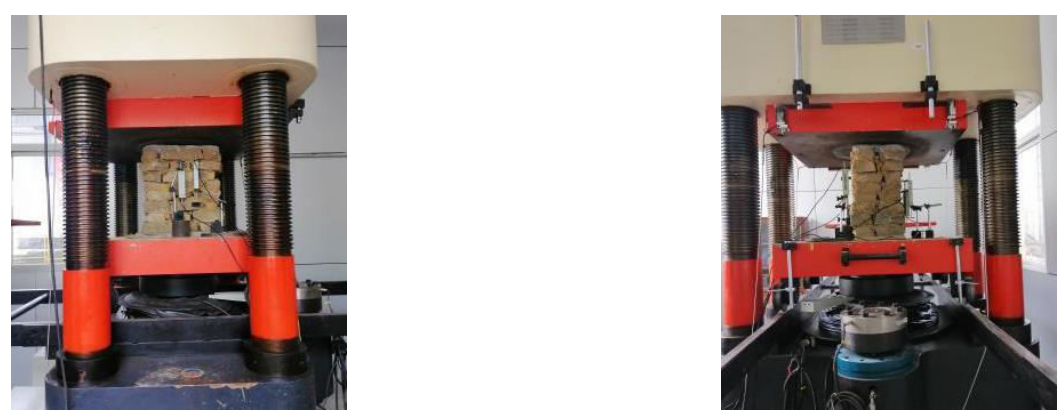

(a) (b)

Figure 3Loading setup on the testing devices: (a) clay caulking specimens; (b) gravel caulking specimens.

Figure 4 shows the measured compressive stress-strain curves of rubble prisms constructed using two different masonry processes, i.e., clay caulking and gravel caulking. The stress was obtained by dividing the compressive load by the cross-sectional area (F/A), and the strain was calculated by dividing the amount of axial compression of the specimen by its initial height $\left(\Delta_{\mathrm{H}} / \mathrm{H}\right)$. To reduce the impact of cracks on the mechanical properties of the specimens during the initial compression stage [8, 20, 22], the slope within the peak load of $30-60 \%$ was used to express the elasticity modulus of Tibetan rubble stone masonry. Table 5 shows the parameters of the masonry, e.g., the compressive strength and the elasticity modulus, which were derived from the measured results 


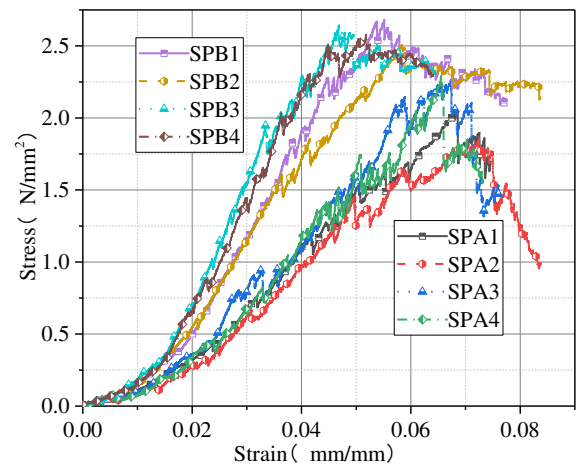

Figure 4 Measurement of full stress-strain curves of compressive strength

Table 5 Basic mechanical parameters of specimens

\begin{tabular}{llllllll}
\hline $\begin{array}{l}\text { Type and No. of } \\
\text { specimens }\end{array}$ & $\begin{array}{l}\text { Cracking } \\
\text { load } f_{c r} \\
(\mathrm{kN})\end{array}$ & $\begin{array}{l}\text { Peak } \\
\text { load } \\
f_{p}(\mathrm{kN})\end{array}$ & $\begin{array}{l}\text { Initial } \\
\text { cracking } \\
\text { coefficient } \\
f_{c r} / f_{p}\end{array}$ & $\begin{array}{l}\text { Compressive } \\
\text { strength } \\
f_{c}(\mathrm{MPa})\end{array}$ & $\varepsilon_{p}$ & $\begin{array}{l}\mathrm{E}(30-60 \%) \\
(\mathrm{MPa})\end{array}$ \\
\hline Clay & 1 & 109.9 & 294.1 & 0.374 & 2.04 & 0.069 & 40.38 \\
caulking & 2 & 96.0 & 271.9 & 0.353 & 1.86 & 0.072 & 37.49 \\
specimens & 3 & 109.6 & 309.5 & 0.354 & 2.26 & 0.067 & 38.19 \\
(SPA) & 4 & 95.5 & 325.5 & 0.293 & 2.29 & 0.066 & 49.77 \\
\hline Mean (standard & 102.8 & 300.3 & 0.342 & 2.11 & 0.068 & 41.46 \\
deviation) & $(8.09)$ & $(22.84)$ & $(0.10)$ & $(0.20)$ & $(0.10)$ & $(5.68)$ \\
\hline Gravel & 1 & 155.7 & 383.8 & 0.406 & 2.68 & 0.055 & 69.97 \\
caulking & 2 & 90.7 & 370.4 & 0.245 & 2.50 & 0.058 & 65.51 \\
specimens & 3 & 154.4 & 401.1 & 0.385 & 2.64 & 0.047 & 79.44 \\
(SPB) & 4 & 134.4 & 392.9 & 0.342 & 2.58 & 0.052 & 76.51 \\
\hline Mean (standard & 133.8 & 387.1 & 0.346 & 2.60 & 0.053 & 72.86 \\
deviation) & $(30.34)$ & $(13.16)$ & $(0.10)$ & $(0.10)$ & $(0.10)$ & $(6.65)$ \\
\hline
\end{tabular}

161 Notes: $\varepsilon_{p}$ denotes peak strain, which is the ratio of the peak displacement to the total height of a specimen.

The stress-strain curves in Figure 4 show that although the two different types of prisms behaved differently under vertical loading in terms of deformation, cracking, and failure characteristics, all the specimens underwent the same four general stages: the clay and void compaction stage, the stone unit cracking stage, the compaction strengthening stage, and the 


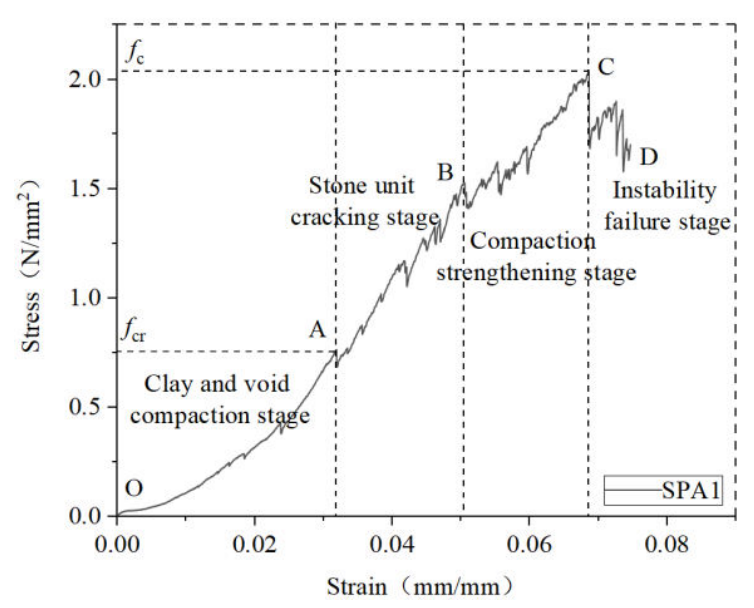

(a)

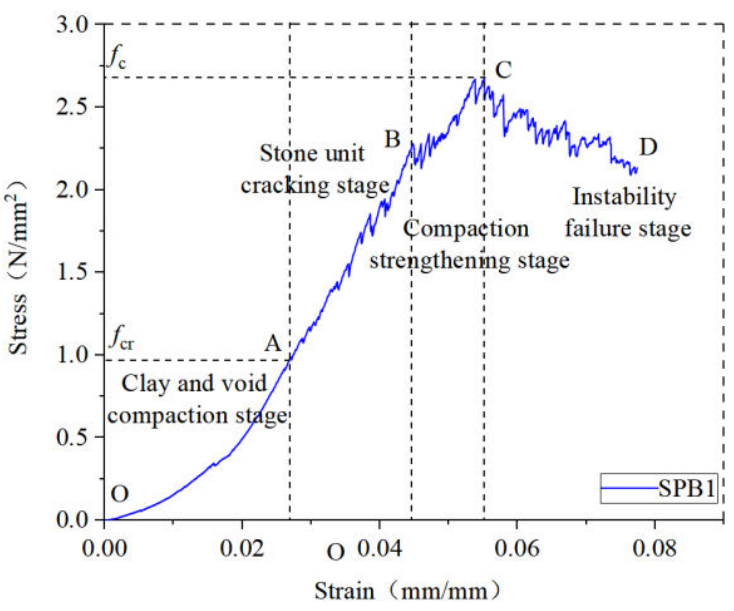

(b)

Figure 5 Typical variation stages of the stress-strain curves: 6) clay fill; 16) gravel stone fill

The following paragraphs provide summaries of the four stages experienced by the two types of prismatic specimens, from compression to failure. These summaries were based on the test results and the various stages as expressed by the stress-strain curves.

For clay caulking specimens (SPAi), the internal cracks and bonding materials were gradually compacted during initial loading, and the joint layers gradually thinned as the load increased. However, the block material remained nearly unchanged, with the stress-strain curve showing a downward convex trend, as illustrated by Stage O-A in Figure 5(a). During the stone unit cracking stage, the load changed suddenly after the block material cracked. The stone continued to crack as the load increased, and cracks developed up and down along the vertical joints, causing the curve to present a changing sawtooth growth tendency, as shown in Figure 6(a) and by Stage A-B in Figure 5(a). The amount of compression of the specimens was smaller in this stage than in the previous stage. The specimens were further compressed in the third stage, namely Stage B-C in Figure 5(a), with the amount of compression significantly reduced from that in the previous two stages. The cracks penetrated along the vertical joints to form vertical run-through crack, as shown in Figure 6(b). The out-of-plane displacement increased with obvious gaps between two stone layers, and the compression curve became fluctuated, forming an ascending section similar to that in the first stage. During Stage C-D in Figure 5(a), the instability failure stage, the gaps between the two layers and the out-of-plane displacements increased sharply and the specimens experienced instability failure, as shown in Figure 6(c).

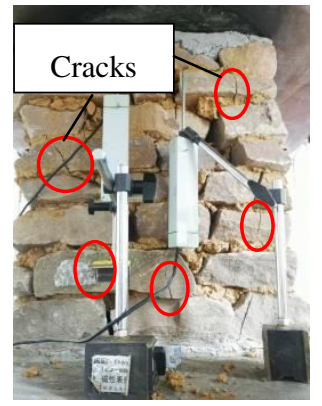

(a)

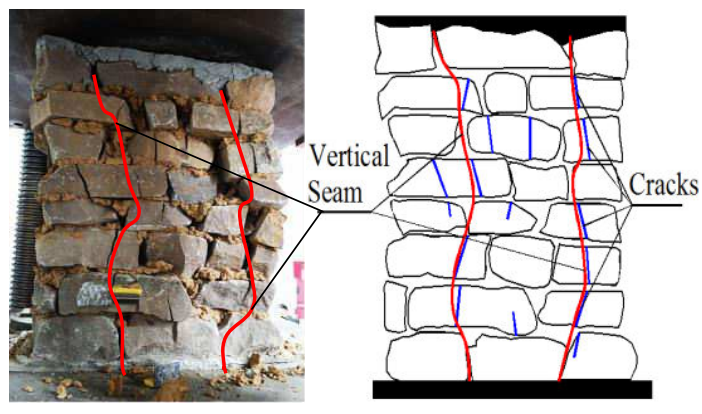

(b)

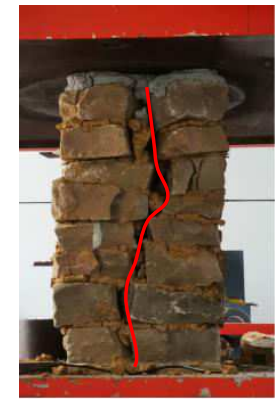

(c)

Figure 6. Typical stages of compression failure of clay caulking specimens (SPA1): (a) cracking of stone elements; (b) formation of vertical through joints; (c) instability failure 
Generally, the compression of the gravel caulking specimens (SPBi) was similar to that of the clay caulking specimens, and could be divided into approximately the same four stages (Figure 5(b)). Similarly to the clay caulking specimens, the gravel caulking specimens underwent some linear elastic changes in the initial compression stage, with less axial compression. The stress in the cracking sections of the stones changed less and the slope of the curve was larger. In the compaction strengthening stage, the gravel caulking specimens had visibly reduced compaction and significantly increased strengthening. In the instability failure stage, the curve for the gravel caulking specimens descended more gently than that for the clay caulking specimens, with the stripping of the two stone layers less obvious than that of the clay caulking specimens.

To further study the mechanical characteristics of Tibetan rubble stone masonry, compression tests were conducted on two groups (six pieces) of small prismatic specimens with dimensions of $500 \times 300 \times 400 \mathrm{~mm}$ (consistent with research results obtained by Garcia et al. [18-20]). Results acquired including the compressive strength and the elasticity modulus (Table 6), as well as failure processes and morphologies similar to those described above.

6 The compressive strength and the elasticity modulus of small prismatic specimens

\begin{tabular}{llllllllll}
\hline $\begin{array}{l}\text { Type and No. of } \\
\text { specimens }\end{array}$ & SSPA1 & SSPA2 & SSPA3 & Mean & SSPB1 & SSPB2 & SSPB3 & Mean \\
\hline $\begin{array}{l}\text { Compressive } \\
f_{c}(\mathrm{MPa})\end{array}$ & strength & 2.79 & 2.89 & 2.70 & 2.80 & 3.22 & 3.59 & 3.59 & 3.47 \\
$\mathrm{E}(30-60 \%)(\mathrm{MPa})$ & 29.96 & 28.92 & 37.76 & 31.72 & 60.43 & 63.41 & 76.86 & 66.41 \\
\hline
\end{tabular}
representing clay caulking specimens and B denoting gravel caulking specimens.

\section{4. Constitutive Models}

212 The stress-strain curves show that each group of specimens presented some distinctness; 213 however, they all followed a similar four-stage variation trend. To study the common 214 variation features of stress-strain curves of the two types of rubble stone masonry structures 215 under compression and establish a unified constitutive model, the stress-strain curves were 216 non-dimensionalized. With the ratio of the compression axial stress to peak stress $\left(\sigma / \sigma_{c}\right)$ as 217 the $\mathrm{Y}$ coordinate and the ratio of axial strain to peak stress corresponding to peak strain $\left(\varepsilon / \varepsilon_{P}\right.$ 218 ) as the $\mathrm{X}$ coordinate, dimensionless stress-strain characteristic curves were drawn in Figure 8.

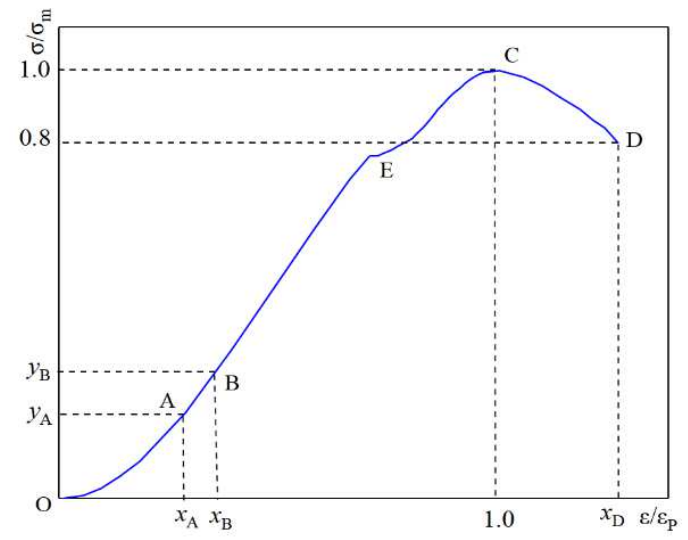

Figure 8Typical dimensionless stress-strain characteristic curves of Tibetan rubble stone masonry. 
In Figure 8, all points of the characteristic curves were analyzed based on the whole compression processes of the prismatic specimens, and it was observed that Points A-E had clear physical significance. Point A marks the end of the compaction of clay with cracks, Point $B$ is the macroscopic cracking point with corresponding to the cracking load, point $C$ is the peak strength point of the specimens, point $\mathrm{D}$ refers to the instability failure point, and Point $\mathrm{E}$ is the initial point of continuous compaction and strengthening peculiar to Tibetan rubble stone masonry. Overall, the growth rate of compressive strength in the rising section increased first, then remained constant, and finally decreased. The curve was approximately a straight line when the specimens were under stable stress, and the slope of the curve was zero when the peak strength (Point C) was reached, which was similar to the characteristic curves of ordinary brick masonry structures. In this study, the boundary conditions of the ascending and descending sections of the compression characteristic curves for Tibetan rubble stone masonry structures were described by the following mathematical relationships:

(1) $x=1.0, y=1.0$;

(2) $x=1.0, \quad y=1.0$, and $\left.\frac{d y}{d x}\right|_{x=1.0}=0$;

(3) When $x<x_{\mathrm{A}}, \frac{d y^{2}}{d x^{2}}>0$; and $\left.\frac{d y^{2}}{d x^{2}}\right|_{x=x_{A}}=0$, there is an inflection point in the ascending section of the curve; when $x_{\mathrm{E}}<x<1.0, \frac{d y^{2}}{d x^{2}}<0$;

(4) For the full curve, when $x \geq 1,0 \leq y \leq 1$.

Based on currently available constitutive equations of masonry structures with weak joints or large numbers of voids [22, 25, 26], a simple two-step empirical equation was adopted, in which the ascending section was expressed by a simple rational fraction (Equation (13)), and the descending section was expressed by a simple parabolic quadratic equation (Equation (14)).

$$
\begin{aligned}
& y=\frac{x}{a x^{2}+b x+c} \\
& y=m x^{2}+n x+p
\end{aligned}
$$

By substituting Equations (13) and (14) into the above boundary conditions, a two-step equation, Equation (15), was obtained:

$$
\frac{\sigma}{\sigma_{c}}= \begin{cases}\frac{\varepsilon / \varepsilon_{p}}{a\left(\varepsilon / \varepsilon_{p}\right)^{2}+\left((1-2 a) \varepsilon / \varepsilon_{p}+a\right.} & 0 \leq \varepsilon \leq \varepsilon_{p} \\ m\left(\varepsilon / \varepsilon_{p}\right)^{2}-2 m\left(\varepsilon / \varepsilon_{p}\right)+1+m & \varepsilon \geq \varepsilon_{p}\end{cases}
$$

In Equation (15), parameter $a$ denotes the ratio of the secant modulus corresponding to the peak point of prismatic specimens to the initial tangent modulus.

Although the above two-step equation reflects well the whole process of Tibetan rubble stone masonry under uniaxial compression, the equation was obtained based on discrete and limited test data. Additionally, once built, Tibetan rubble stone masonry will complete the compaction of clay and voids under the influence of self-weight, which causes the first stage of compression to be approximately an elastic state. Hence, the above constitutive model has some limitations. To reduce the impact of data dispersion, the compression constitutive model 
was modified based on damage theory and probability statistics. First, the initial concave part of the stress-strain curve was simplified and replaced by a straight line, making it more consistent with practical conditions and convenient for application. Silva et al. [13] replaced the initial concave portion of the curve with a convex parabola. When simplifying the curve in this study, a straight line with a slope of $\mathrm{E}$ was used to replace the curve before the inflection point of the concave ascending section, and the origin of the coordinates was moved to the intersection of the straight line and the $\mathrm{x}$ axis (residual deformation). Figure 9 shows the simplified stress-strain curve.

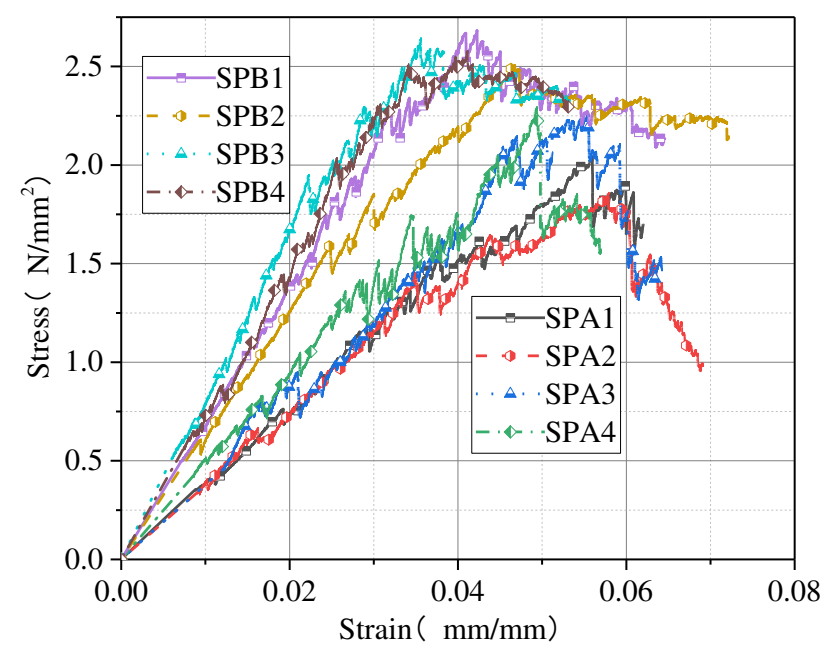

Figure 9Simplified stress-strain curves

265
Tibetan rubble stone masonry is a quasi-brittle material whose damage type is similar to that of brick masonry. Its damage refers to brittle damage caused by the propagation of discontinuous initial micro-cracks as well as the initiation and propagation of new micro-cracks. From a macroscopic perspective, the specimens were broken into several small columns parallel to the stress direction under uniaxial compression. Then, the evolutionary pattern of damage of Tibetan rubble stone masonry under uniaxial compression was simulated with reference to the parallel bar model (PBS), a meso-statistical damage model. A specimen was divided into $\mathrm{N}$ elastic links with equal areas along the vertical compressive stress, and the upper and lower sides of the specimen were connected by rigid bodies to ensure coordinated and equal deformation of each link in the direction of vertical compressive stress. The masonry would produce certain strain under an axial compressive load. According to the principle of continuous damage mechanics and strain equivalence [27], damaged materials satisfy the following constitutive relationship:

$$
\sigma=E(1-D) \varepsilon
$$

In Equation (16), E denotes the elasticity modulus of the masonry, $\varepsilon$ is the compressive strain, and $\mathrm{D}$ is the damage variable that refers to damage caused by compressive stress.

Previous studies have shown that when quasi-brittle materials such as brick masonry and rock are damaged, their breaking strengths obey the Weibull statistical distribution [28,29]. The failure of Tibetan rubble stone masonry was assumed to obey the Weibull statistical distribution, and the probability density of the strengths of the rubble micro-elements was defined as 


$$
\varphi(x)=\frac{m}{a}\left(\frac{m}{a}\right)^{m-1} \cdot \exp \left[-\left(\frac{x}{a}\right)^{m}\right]
$$

where a and $\mathrm{m}$ are the parameters of the Weibull distribution.

The macro-damage of the masonry is a conglomeration of the damage and deterioration of meso-elements. The development of the masonry structure from an undamaged state to a completely damaged state is a continuous process where the damage increases over time. Therefore, a damage variable, $\mathrm{D}$, was defined:

$$
D(\varepsilon)=\int_{0}^{\varepsilon} \varphi(x) d x=\int_{0}^{\varepsilon}\left\{\frac{m}{a}\left(\frac{x}{a}\right)^{m-1} \cdot \exp \left[-\left(\frac{x}{a}\right)^{m}\right]\right\} d x=1-\exp \left[-\left(\frac{\varepsilon}{a}\right)^{m}\right]
$$

By substituting the damage variable into the stress-strain relationship, Equation (19) was obtained:

$$
\sigma=E(1-D) \varepsilon=E \varepsilon \cdot \exp \left[-\left(\frac{\varepsilon}{a}\right)^{m}\right]
$$

The values of $a$ and $m$ in Equation (19) were determined by the uniaxial compression tests. According to the characteristics and boundary conditions of stress-strain curves for masonry under uniaxial compression, a constitutive model for Tibetan rubble stone masonry under uniaxial compression was developed:

$$
\sigma(\varepsilon)=E \varepsilon \cdot \exp \left[-\frac{1}{m}\left(\frac{\varepsilon}{\varepsilon_{p}}\right)^{m}\right]
$$

To compare the experimental results with the results obtained by the stress-strain relationship prediction model, Equation (20) and the stress-strain curve were normalized, and Equation (21) was obtained:

$$
\frac{\sigma}{\sigma_{c}}=\frac{E \varepsilon_{p}}{\sigma_{c}} \cdot \frac{\varepsilon}{\varepsilon_{p}} \cdot \exp \left[-\frac{1}{m}\left(\frac{\varepsilon}{\varepsilon_{p}}\right)^{m}\right]
$$

When $\sigma / \sigma_{c}=y$ and $\varepsilon / \varepsilon_{p}=x$, the constitutive relationship could be simplified:

$$
y=x \cdot \exp \left[\frac{1}{m}\left(1-x^{m}\right)\right]
$$
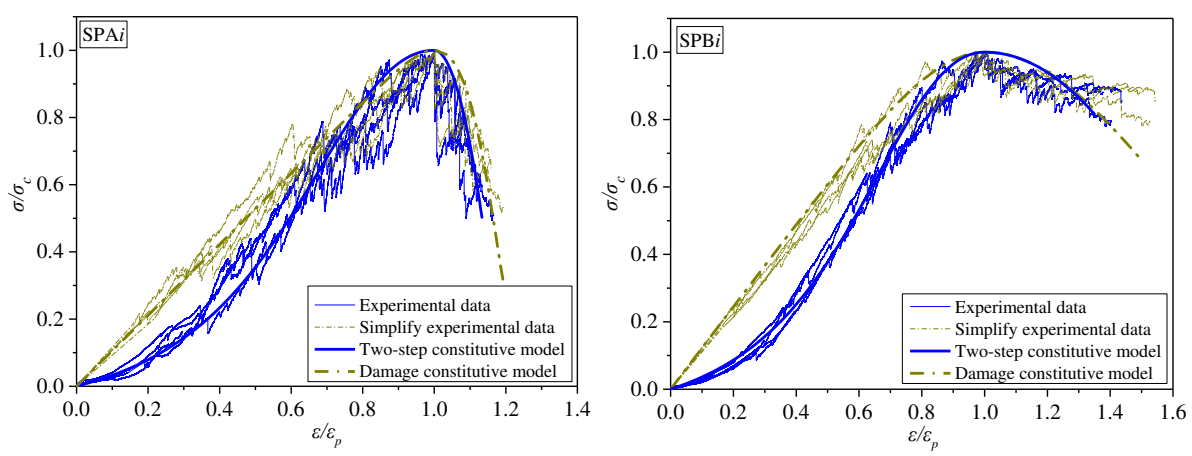
(a)

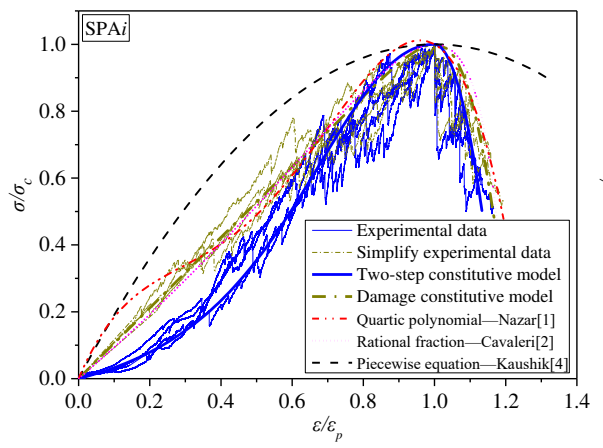

(c) (b)

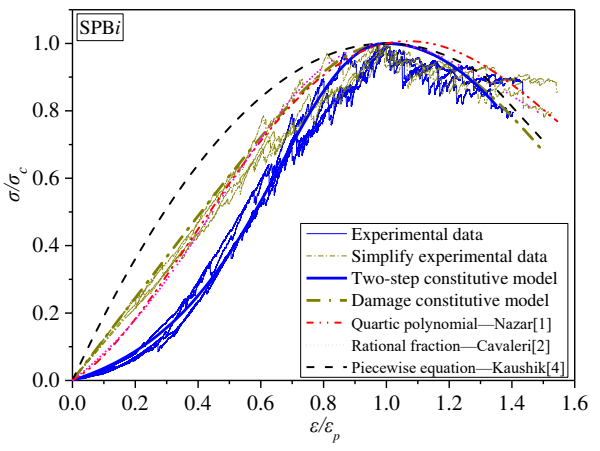

(d)

Figure 10. Comparison of results obtained by the stress-strain prediction model and the experimental results: (a) Comparison of the proposed model with experimental results of SPAi; (b) Comparison of the proposed model with experimental results of SPBi; (c) Comparison of the models from literature with experimental results of SPAi; (d) Comparison of the models from literature with experimental results of SPBi.

Figure 10 compares the results obtained by the stress-strain prediction model and the experimental results. In general, the two models proposed in this study were consistent with the stress-strain curves from the experimental results. The prediction models proposed by Nazar [1] and Cavaleri [2] agree with the simplified stress-strain curves. However, there are differences between them in the initial compression stage. The parabolic prediction model proposed by Kaushik [4] is not applicable to predicting the stress-strain curves of Tibetan rubble stone masonry. During the instability failure stage, the resistance forces of Tibetan rubble stone masonry come from the adhesive forces between blocks, so the descending section of the curve had discrete features, and many models had poor prediction performance for this section.

\section{Prediction of Compressive Strengths}

As shown in Tables 3 and 6, the compressive strength of rubble prisms is characterized by discrete features, and the gravel caulking masonry process with an improved bonding material could improve the bearing capacity of the masonry structures by about $23 \%$. The two rubble stone masonry structures with different masonry processes generally had low compressive strengths. These results are similar to results obtained by Garcia et al. [18-20], who stuck natural stones together with weak joint mortars such as lime. To compare prismatic specimens with standard specimens defined by relevant codes in terms of compressive strength, based on the influences of the height-thickness ratio $(\mathrm{h} / \mathrm{t})$ of masonry on its compressive strength (as emphasized by Gumaste et al. [30, 31]), this study's experimental results were corrected with specific revised parameters and the results are shown in Table 7.

Table 7 Corrected height to thickness ratio and strength

\begin{tabular}{lllll}
\hline $\begin{array}{l}\text { Type and No. of } \\
\text { specimens }\end{array}$ & $\begin{array}{l}\text { Height to } \\
\text { thickness ratio } h / t\end{array}$ & $\begin{array}{l}\text { Correction } \\
\text { coefficient }\end{array}$ & $\begin{array}{l}\text { Corrected } \\
\text { strength (MPa) }\end{array}$ & $\begin{array}{l}\text { Average } \\
\text { strength } \\
\text { after }\end{array}$ \\
\hline
\end{tabular}




\begin{tabular}{llllll}
\hline & & & & & $\begin{array}{c}\text { correction } \\
\text { (MPa) }\end{array}$ \\
\hline Clay caulking & 1 & 2.00 & 0.730 & 1.489 & 1.553 \\
specimen (SPA) & 2 & 2.07 & 0.740 & 1.376 & \\
& 3 & 2.05 & 0.737 & 1.666 & \\
& 4 & 2.03 & 0.734 & 1.681 & 1.895 \\
Gravel caulking & 1 & 2.03 & 0.734 & 1.967 & \\
specimen (SPB) & 2 & 1.98 & 0.726 & 1.815 & \\
& 3 & 1.97 & 0.725 & 1.914 & \\
& 4 & 2.00 & 0.730 & 1.883 & \\
\hline
\end{tabular}

The corrected compressive strength results were compared with results calculated by standard equations and currently available masonry compressive strength prediction equations (Table 2). The comparison is provided in Table 8.

Table 8Comparison of theoretical and experimental results

\begin{tabular}{lll}
\hline & Clay caulking & Gravel caulking \\
\hline Kaushik et al. [4] & 5.840 & 6.351 \\
Eurocode [5] & 8.666 & 9.376 \\
Dayaratnam et al. [6] & 2.668 & 3.042 \\
Hendry and Malek [7] & 3.540 & 3.739 \\
Adrian Costigan et al. [8] & 4.462 & 5.088 \\
GB 50003-2011 [9] & 1.461 & 1.658 \\
This study & 1.553 & 1.895 \\
\hline
\end{tabular}

As shown in Table 8, most of the theoretical values differed significantly from the experimental results because each prediction equation was developed for specific materials and masonry types. García et al. [18, 19] noted that predicting the compressive strength of low-strength mortar masonry using these equations would lead to large errors, especially when the ratio of block strength to mortar strength exceeded 10, and the prediction results were unreliable. Considering the complexity and discontinuity of Tibetan rubble stone masonry structures, and according to currently available methods in defining the parameters in the prediction equations, a prediction equation (Equation (23)) was developed. This equation was established using regression methods based on this study's experimental data and is suitable for predicting the compressive strength of Tibetan rubble stone masonry.

$$
f_{c}=0.44 f_{b}^{0.28} \cdot f_{m}^{0.72}
$$

\section{Relationship between Compressive Strength and Elasticity Modulus}

To design the masonry structure, the relationship between compressive strength and the elasticity modulus was analyzed. Though the two parameters were not theoretically correlated, there is practical value in exploring the relationship between the two[10]. According to the experimental results, the elasticity modulus of Tibetan rubble stone masonry structures built by two different masonry processes (i.e., clay caulking and gravel caulking) were within the ranges of 37.49-49.77 $\mathrm{MPa}$ and 65.51-79.44 MPa. To reflect the relationship between the elasticity modulus and the compressive strength as precisely as 
possible, many data were collected for the compressive strength of Tibetan rubble stone masonry. Using linear regression on the collected results and this study's experimental results (Figure 11), relationships between the elasticity modulus and the compressive strength of clay caulking specimens andgravel caulking specimens were obtained as $E_{m}=16.89 f_{m}$ and $E_{m}=22.44 f_{m}$, respectively.
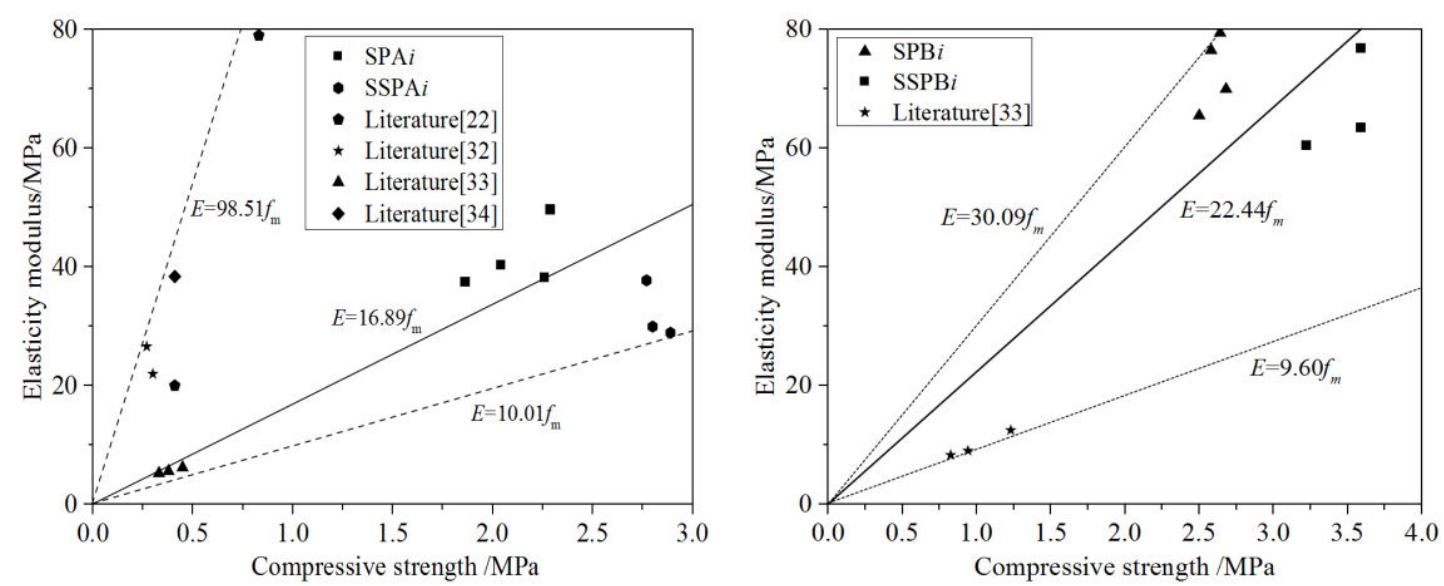

Figure 11Relationship between the compressive strength and the elasticity modulus of rubble stone masonry

\section{Conclusions}

This study used compression tests on typical rubble prismatic specimens to explore the compression failure mode and stress mechanisms of prismatic specimens. A comparative analysis of compressive strength and stress-strain characteristics was also performed, and the following conclusions were obtained:

1. Due to the irregular shapes and sizes of natural stones, different masonry techniques, and the uncertainty of the geometric arrangement of the block materials, the compressive mechanical properties of Tibetan rubble stone masonry are characterized by significant discreteness. Therefore, unlike the stress-strain curves for ordinary brick masonry structures, the curves for the entire compression processes of Tibetan rubble stone masonry show significant nonlinear characteristics.

2. The stress-strain curves for different Tibetan rubble stone masonry specimens follow specific patterns. In this study, two simple constitutive models were proposed based on the general trend of these curves.

3. Based on this study's experimental results, equations were developed to predict the compressive strength of Tibetan rubble stone masonry. Combined with currently available research results, the linear relationship between the compressive strength and the elasticity modulus of Tibetan rubble stone masonry was established through regression analysis.

Funding: This research was funded by The National Natural Science Foundation of China (51568058). This support is gratefully acknowledged. 


\section{References}

384 [1] Nazar, M. E. , \& Sinha, S. N. . (2007). Loading-unloading curves of interlocking grouted stabilised

[2] Cavaleri, L. , Failla, A. , Mendola, L. L. , \& Papia, M. . (2005). Experimental and analytical response of masonry elements under eccentric vertical loads. Engineering Structures, 27(8), 1175-1184. doi: 10.1016/j.engstruct.2005.02.012

[3] Augenti, N. , \& Parisi, F. . (2010). Constitutive models for tuff masonry under uniaxial compression. Journal of Materials in Civil Engineering, 22(11), 1102-1111. doi: 10.1061/(ASCE)MT.1943-5533.0000119

[4] Kaushik, H. B. , Rai, D. C. , \& Jain, S. K. . (2007). Stress-strain characteristics of clay brick masonry under uniaxial compression. Journal of Materials in Civil Engineering, 19(9), 728-739. doi: 10.1061/(ASCE)0899-1561(2007)19:9(728)

[5] Eurocode 6 . (2005). Designofmasonry structures-Part 1-1: General rules for buildings-Rulesfor reinforced and unreinforced masonry. Brussels: European Committee for Standardization

[6] Dayaratnam P. .(1987). Brick and reinforced brick structures. South Asia Books

[7] Ferretti, D. . (2020). Dimensional analysis and calibration of a power model for compressive strength of solid-clay-brick masonry. Engineering Structures, 205. doi: 10.1016/j.engstruct. 2019.110064

[8] Costigan, A. , Pavia, S. , \& Kinnane, O. . (2015). An experimental evaluation of prediction models for the mechanical behavior of unreinforced, lime-mortar masonry under compression. Journal of Building Engineering, 4(1), 283-294. doi: 10.1016/j.jobe. 2015.10.001

[9] GB 50003. (2011). Code for design of masonry structures. China Ministry of Construction,Beijing (in Chinese)

[10] Zhou, Q. , Wang, F. , Zhu, F. , \& Yang, X. . (2017). Stress-strain model for hollow concrete block masonry under uniaxial compression. Materials \& Structures, 50(2), 106. doi: 10.1617/s11527-016-0975-5

[11] Lumantama, R. , Biggs, D. T. , \& Ingham, J. M. . (2014). Uniaxial compressive strength and stiffness of field-extracted and laboratory-constructed masonry prisms. Journal of Materials in Civil Engineering, 26(4), 567-575. doi: 10.1061/(ASCE)MT.1943-5533.0000731

[12] Pinho, F. F. S. , Válter J. G. Lúcio, \& Manuel F. C. Baião. (2012). Rubble stone masonry walls in portugal strengthened with reinforced micro-concrete layers. Bulletin of Earthquake Engineering, 10(1), 161-180. doi: 10.1007/s10518-011-9280-4

[13] Silva, B. , Pigouni, A. E. , Valluzzi, M. R. , \& Modena, C. . (2014). Calibration of analytical formulations predicting compressive strength in consolidated three-leaf masonry walls. Construction \& Building Materials, 64, 28-38. doi: 10.1016/j.conbuildmat.2014.04.044

[14] Valluzzi, M. R. , Porto, F. D. , \& Modena, C. . (2001). Behaviour of multi-leaf stone masonry walls strengthened by different intervention techniques. Historical Constructions, 1023-1032. doi: http://dx.doi.org/

[15] Valluzzi, M. R. , Porto, F. D. , \& Modena, C. . (2004). Behavior and modeling of strengthened three-leaf stone masonry walls. Materials \& Structures, 37(267), 184-192. doi: 10.1007/BF02481618

[16] Almeida, C., Guedes, J. P., Arede, A., Costa, C. Q., \& Costa, A. (2012). Physical characterization and compression tests of one leaf stone masonry walls. Construction \& Building Materials,30, 188-197. doi: 10.1016/j.conbuildmat.2011.11.043

[17] Oliveira, D. V. , Silva, R. A. , Garbin, E. , \& Louren?O, P. B. . (2012). Strengthening of three-leaf stone masonry walls: an experimental research. Materials and Structures, 45(8), 1259-1276. doi: 10.1617/s11527-012-9832-3

[18] Garcia, D. , San-Jose, J. T. , Garmendia, L. , \& San-Mateos, R. . (2012). Experimental study of traditional stone masonry under compressive load and comparison of results with design codes. Materials \& Structures, 45(7), 995-1006. doi: 10.1617/s11527-011-9812-z

[19] Garcia, D. , San-Jose, J. T. , Garmendia, L. , \& Larrinaga, P. . (2012). Comparison between experimental values and standards on natural stone masonry mechanical properties. Construction \& Building Materials,28(1), 444-449. doi: 10.1016/j.conbuildmat.2011.08.012 
[20] Meimaroglou, N. , \& Mouzakis, H. . (2018). Mechanical properties of three-leaf masonry walls constructed with natural stones and mud mortar. ENGINEERING STRUCTURES

[21] CEN (2003) Eurocode 6: design of masonry structures. EN 1996-1-1:2003, CEN, Brussels, Belgium

[22] Teng, D. Y. , \& Yang, N. . (2018). Research on the features of complete stress-strain curves of tibetan-style stone masonry under compressive load. Engineering Mechanics. doi: 10.6052/j.issn.1000-4750.2017.08.0647 (in Chinese)

[23] GB/T 50129. (2011). Standard test method for basicmechanical properties of masonry. China Ministry of Construction,Beijing (in Chinese)

[24] EN 1052-1. (1999). Methods of test for masonry: part 1-determination of compressive strength

[25] Zhao, C. , Tuohuti, A. , Chen, J. , \& Qin, Y. J. . (2010). Researches on modified raw-soil materials constitutive relation subject to uniaxial compression. Journal of Xinjiang University(Natural Science Edition) (in Chinese)

[26] Zhong, J. Q. .(2018). Study and application on constitutive relationship for earth material and mechanical compressed earth brick masonry. PhDthesis, Chang'an University (in Chinese)

[27] De, S. N. E. A. , Peri, D. , \& Owen, D. R. J. . (2008). Damage Mechanics. John Wiley \& Sons, Ltd. doi: 10.1002/9780470694626.ch12

[28] Gu, D. D. . (2011). On a statistical damage constitutive model for rock materials. Computers \& Geosciences,37(2), 122-128. doi: 10.1016/j.cageo.2010.05.018

[29] Wong, T. F. , Wong, R. H. C. , Chau, K. T. , \& Tang, C. A. . (2006). Microcrack statistics, weibull distribution and micromechanical modeling of compressive failure in rock. Mechanics of Materials, 38(7), 664-681. doi: 10.1016/j.mechmat.2005.12.002

[30] Gumaste, K. S. , Rao, K. S. N. , Reddy, B. V. V. , \& Jagadish, K. S. . (2007). Strength and elasticity of brick masonry prisms and wallettes under compression. Materials \& Structures, 40(2), 241-253. doi: 10.1617/s11527-006-9141-9

[31] British Standards Institution. Code of practice for use of masonry. structural use of unreinforced masonry

[32] Hung, H. , Yang, D. , Chen, K. , et al. (2020). Experiments on mechanical performance of tibetan rubble stone walls retrofitted with BFRP grids. Journal of Southwest Jiaotong University, 55(3) : 643-649 (in Chinese)

[33] Ji, Z. .(2017). Experimental research on compressive performance of Tibetan dwellings rough wall. Master'sthesis, SouthwestUniversityofScienceandTechnology (in Chinese)

[34] Fu, L. .(2016). The improved technology of compression performance of the rubble masonry walls of Tibet folk dwelling. Master'sthesis, SouthwestUniversityof ScienceandTechnology (in Chinese) 